\title{
The effect of diet on ileostomy function
}

\author{
T. J. THOMSON, J. RUNCIE, AND A. KHAN
}

From the Gastrointestinal Unit, Stobhill and Ruchill Hospitals, Glasgow, and the University Department of Materia Medica, Stobhill Hospital, Glasgow

SUMMARY A questionnaire was sent to 5,100 members of the Ileostomy Association of Great Britain and Ireland inviting the members to record their experiences in relation to the function of the ileostomy following on the ingestion of 29 named articles of diet. Nine hundred and fifty-two people, 623 females $(65.4 \%)$ and 329 males $(34.6 \%)$, completed the questionnaire satisfactorily. The group showed a close similarity to the total distribution found by the Association with regard to age, sex, and duration of ileostomy.

Analysis of the data showed that the great majority of patients with an ileostomy have no difficulty in choosing a diet. The effects of various items of diet on functions of the ileostomy are analysed with special reference to the production of watery flow, upset of timing of filling of the bag, flatulence, pain, and odour.

It is concluded that an individual patient with an ileostomy should not omit any article from his diet unless he has found that it repeatedly causes dyspepsia.

One question in the minds of many people with a permanent ileostomy is whether they should eat a normal mixed diet or avoid specific items which might cause upset of bowel function. When our advice on this topic was sought by patients with an ileostomy we turned for the answer to standard medical textbooks.

We were surprised to find very little detailed information about the content of the diet which the ileostomy patient should take. Dunlop, Alstead, and Macgregor (1968) state: 'The patient with an ileostomy will find out by experience any special foodstuffs which seem to stimulate the ileum and will learn to avoid them.' Jones, Gummer, and Lennard-Jones (1968) write: 'They can eat an almost normal diet'. There is very little information available on the effects which specific articles of diet may have on the function of an ileostomy. Kramer, Kearney, and Ingelfinger (1962), in a study of seven healthy ileostomy patients, found that of 12 selected foods and liquids, only prune juice consistently increased

Received for publication 21 November 1969. the wet weight and other characteristics of the ileal effluent.

In order to collect factual data on the relationship between diet and the function of an ileostomy, we decided to invite a large number of persons with an ileostomy to record their experiences following the ingestion of named articles of diet. This communication describes the results of this enquiry.

\section{Method}

A questionnaire was sent to 5,100 members of the Ileostomy Association of Great Britain and Ireland who were each requested to complete the form (Fig. 1) and return it for analysis. The age, sex, change in weight, and time interval from the date of operation were recorded. Each patient was asked to indicate whether or not each of the listed items of diet which had been taken since operation caused any upset in the function of the ileostomy; illustrative examples were shown on 
ILEOSTOMY AND DIET

A. Age...... Sex Male/Female Duration of Ileostomy.... yrs.

B. Is your weight (a) rising (b) falling (c) steady?

C. Do you have any difficulty in choosing diet? Yes/No

D. Foods (and drinks) taken since date of operation.

The following list of items is to be considered. Please put a tick in columns (1) to (6) against each item of food (or drink) which has been taken since date of operation.

Columns (1) to (6) are explained below the list of items. Columns (1) to (5) refer to items causing trouble and column (6) to items which cause no trouble.

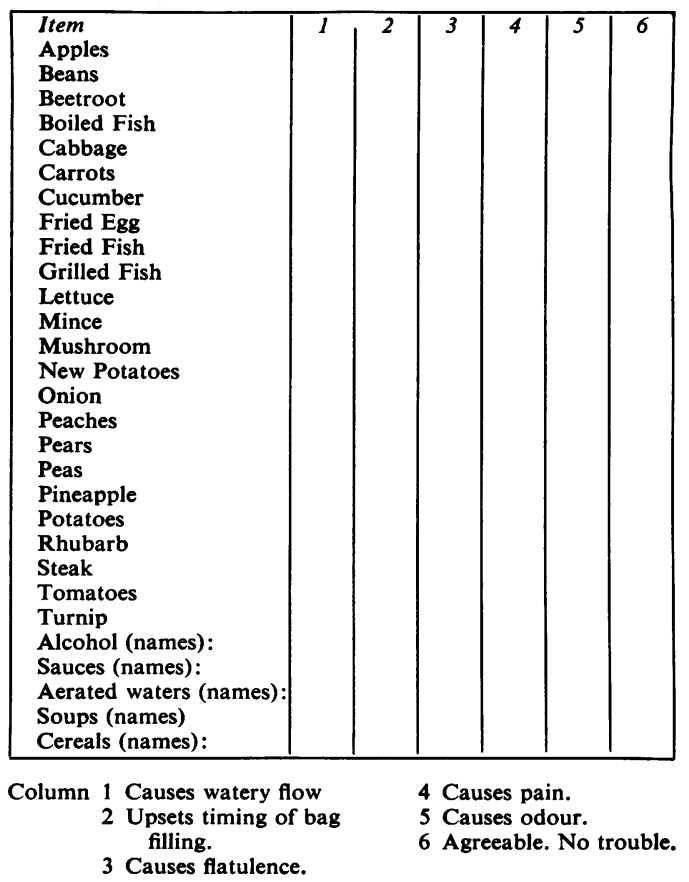

Fig. 1 The questionnaire.

\begin{tabular}{ll|l|l|l|l|l|l|} 
& 1 & 2 & 2 & 4 & 5 & 6 \\
\cline { 2 - 6 } & & & & & & & $\sqrt{ }$ \\
\end{tabular}

If apples cause no trouble, you would put a tick in column 6 .

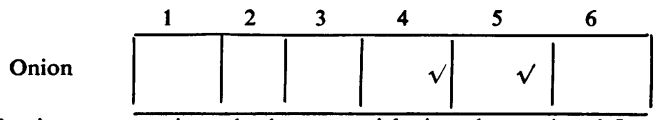

If onion causes pain and odour, put ticks in columns 4 and 5.

Fig. 2 An illustrative example from the questionnaire.

the questionnaire (Fig. 2). The information was transferred to 80-column punch cards and analysed by a counter-sorter and card-reader linked to an electric typewriter.

\section{Results}

The questionnaire was completed satisfactorily by 952 people, 623 females $(65.4 \%)$ and 329 males $(34 \cdot 6 \%)$.

The age distribution of the series is illustrated in

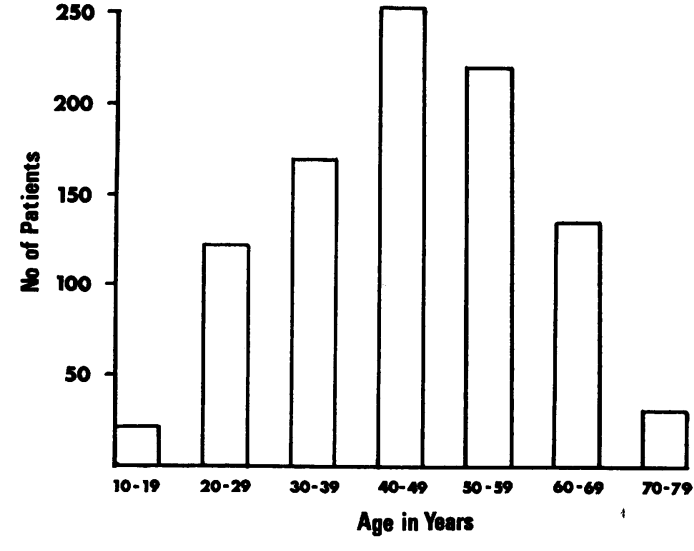

Fig. 3 Age distribution of the 952 patients.

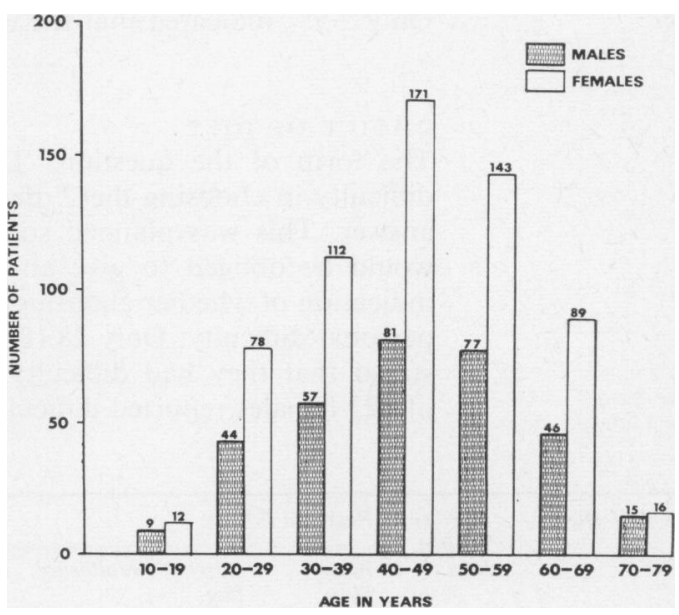

Fig. 4 Distribution by age and sex.

Figure 3. Fifty per cent were between 40 and 59 years; there were 21 patients below the age of 19, and 31 in the range 70 to 79 years. Comparison of the age in relation to the sex shows that the percentage of the total in each decade was similar for males and for females (Fig. 4). This compares closely with data relating to the members of the Ileostomy Association in 1968.

DURATION OF ILEOSTOMY

The time intervals from the date of operation were similar for males and females (Fig. 5): $73 \%$ of the patients of either sex had had the ileostomy for between one and 10 years and $19.5 \%$ of the males and $15 \%$ of the females had had the ileostomy for more than 10 years. From records available in 1967 of 3,457 patients in the Ileostomy Association, $72 \%$ had had the operation performed within 10 years. 


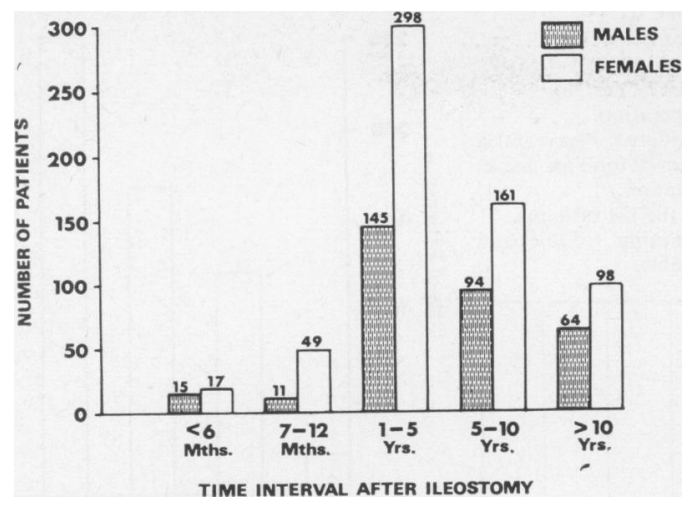

Fig. 5 Duration of the ileostomy.

\section{WEIGHT}

Seventy-four per cent of those completing the questionnaire stated that their weight was steady. Only $2.5 \%$ indicated that the weight was falling.

\section{CHOICE OF DIET}

The form of the question, 'Do you have any difficulty in choosing diet?' demanded a specific answer. This was planned so that each patient would be obliged to give an overall subjective indication of whether choosing a diet gave rise to personal difficulty. Only $28(8.5 \%)$ of 329 males stated that they had difficulty, and $99(15.9 \%)$ of 623 females reported difficulty. It was import-

\begin{tabular}{|c|c|c|c|c|c|c|c|}
\hline \multirow[t]{2}{*}{ Item of Diet } & \multirow{2}{*}{$\begin{array}{l}\text { Number } \\
\text { Taking } \\
\text { Item }\end{array}$} & \multicolumn{6}{|c|}{ Reported Effects ${ }^{1}$} \\
\hline & & $\begin{array}{l}\text { Watery } \\
\text { Flow }\end{array}$ & $\begin{array}{l}\text { Upset of } \\
\text { Bag } \\
\text { Filling }\end{array}$ & Flatulence & Pain & & Odour \\
\hline Apples & 900 & $120(13 \cdot 3)$ & $62(6.9)$ & $58 \quad(6 \cdot 4)$ & 63 & $(7 \cdot 0)$ & $9(1.0)$ \\
\hline Beans & 888 & $61 \quad(6.9)$ & $46(5 \cdot 2)$ & $192(21 \cdot 6)$ & 47 & $(5 \cdot 3)$ & $17(1.9)$ \\
\hline Beetroot & 818 & $104(12 \cdot 7)$ & $50(6 \cdot 1)$ & $35 \quad(4 \cdot 3)$ & 36 & $(4 \cdot 4)$ & $22(2 \cdot 7)$ \\
\hline Boiled fish & 812 & $92(11 \cdot 3)$ & $9(1 \cdot 1)$ & $15(1 \cdot 8)$ & 10 & $(1 \cdot 2)$ & $256(31 \cdot 5)$ \\
\hline Cabbage & 844 & $110(13.0)$ & $52(6.2)$ & $114(13.5)$ & 42 & $(5 \cdot 0)$ & $105(12.4)$ \\
\hline Carrots & 906 & $40 \quad(4 \cdot 4)$ & $24(2 \cdot 7)$ & $36(4 \cdot 0)$ & 30 & $(3 \cdot 3)$ & $8(0.9)$ \\
\hline Cucumber & 734 & $68 \quad(9 \cdot 3)$ & $26(3.5)$ & $139(18.9)$ & 56 & $(7 \cdot 6)$ & $15(2 \cdot 0)$ \\
\hline Fried egg & 884 & $84(9 \cdot 5)$ & $17(1.9)$ & $43(4.9)$ & 15 & $(1 \cdot 7)$ & $110(12.4)$ \\
\hline Fried fish & 908 & $150(16.5)$ & $23(2 \cdot 5)$ & $34(3.7)$ & 20 & $(2 \cdot 2)$ & $343(37 \cdot 8)$ \\
\hline Grilled fish & 871 & $78 \quad(9 \cdot 0)$ & $8(0.9)$ & $9(1.0)$ & 7 & $(0.8)$ & $241(27 \cdot 7)$ \\
\hline Lettuce & 835 & $140(16 \cdot 8)$ & $50(6.0)$ & $73(8 \cdot 7)$ & 42 & $(5 \cdot 0)$ & $13(1 \cdot 6)$ \\
\hline Mince & 883 & $46(5 \cdot 2)$ & $13(1 \cdot 5)$ & $13(1.5)$ & 8 & $(0.9)$ & $21 \quad(2 \cdot 4)$ \\
\hline Mushrooms & 684 & $106(15 \cdot 5)$ & $55(8 \cdot 0)$ & $37 \quad(5 \cdot 4)$ & 65 & $(9 \cdot 5)$ & $17(2 \cdot 5)$ \\
\hline New potatoes & 929 & $47(5 \cdot 1)$ & $18(1.9)$ & $50 \quad(5 \cdot 4)$ & 45 & $(4 \cdot 8)$ & $10(1 \cdot 1)$ \\
\hline Onions & 815 & $136(16 \cdot 7)$ & $44(5.4)$ & $185(22 \cdot 7)$ & 108 & $(13 \cdot 3)$ & $317(38.9)$ \\
\hline Peaches & 891 & $81(9 \cdot 1)$ & $31(3 \cdot 5)$ & $15(1 \cdot 7)$ & 24 & $(2 \cdot 7)$ & $8(0.9)$ \\
\hline Pears & 879 & $127(14 \cdot 4)$ & $32(3 \cdot 6)$ & $36(4 \cdot 1)$ & 23 & $(2 \cdot 6)$ & $8 \quad(0.9)$ \\
\hline Peas & 891 & $59(6 \cdot 6)$ & $65(7 \cdot 3)$ & $211(23 \cdot 7)$ & 67 & $(7 \cdot 5)$ & $25 \quad(2.8)$ \\
\hline Pineapple & 780 & $130(16 \cdot 7)$ & $52(6 \cdot 7)$ & $42(5 \cdot 4)$ & 92( & $(11 \cdot 8)$ & $8(1.0)$ \\
\hline Potatoes & 939 & $10(1 \cdot 1)$ & $4(0.4)$ & $4(0.4)$ & 3 & $(0 \cdot 3)$ & $1 \quad(0 \cdot 1)$ \\
\hline Rhubarb & 707 & $236(33.4)$ & $64(9 \cdot 0)$ & $37 \quad(5 \cdot 2)$ & 48 & $(6 \cdot 8)$ & $14(2 \cdot 0)$ \\
\hline Steak & 929 & $17(1 \cdot 8)$ & $7(0.7)$ & $8(0.9)$ & 14 & $(1 \cdot 5)$ & $8 \quad(0.9)$ \\
\hline Tomatoes & 874 & $98(11 \cdot 2)$ & $36(4 \cdot 1)$ & $22(2 \cdot 5)$ & 28 & $(3 \cdot 2)$ & $7(0.8)$ \\
\hline Turnip & 635 & $56(8 \cdot 8)$ & $27(4 \cdot 3)$ & $106(16 \cdot 7)$ & 26 & $(4 \cdot 1)$ & $22 \quad(3.5)$ \\
\hline Alcohol & 712 & $165(23 \cdot 2)$ & $32(4 \cdot 5)$ & $35(4.9)$ & 15 & $(2 \cdot 1)$ & $29(4 \cdot 1)$ \\
\hline Sauces & 731 & $46(6 \cdot 3)$ & $14(1.9)$ & $19(2 \cdot 6)$ & 18 & $(2 \cdot 5)$ & $16(2 \cdot 2)$ \\
\hline Aerated waters & 691 & $44(6 \cdot 4)$ & $15(2 \cdot 2)$ & $52(7 \cdot 5)$ & 4 & $(0 \cdot 6)$ & $5(0.7)$ \\
\hline Soups & 882 & $133(15 \cdot 1)$ & $36(4 \cdot 1)$ & $45(5 \cdot 1)$ & 9 & $(1 \cdot 0)$ & $27 \quad(3 \cdot 1)$ \\
\hline Cereals & 815 & $36 \quad(4 \cdot 4)$ & $22(2 \cdot 7)$ & $13(1 \cdot 6)$ & 6 & $(0.7)$ & $1(0.1)$ \\
\hline
\end{tabular}

Table II Effect of individual items of diet on the characteristics of ileostomy function

${ }^{1}$ The figures given in brackets are the percentages. ant to determine whether the difficulties altered with the passage of time from the date of operation. Table I shows that the men had a very low incidence of trouble until after 10 years, when it rose to $15.6 \%$, while the women had a much higher incidence of difficulty with choice of diet in the earlier years, and the overall difficulty in both sexes increased after an interval of 10 years.

\begin{tabular}{lrr}
\hline Time after Operation & \multicolumn{1}{c}{ Males } & \multicolumn{1}{c}{ Females } \\
\hline Less than 6 months & $15(6.7 \%)$ & $17(23.5 \%)$ \\
Between 7 and 12 months & $11(0)$ & $49(22.4 \%)$ \\
Between 1 and 5 years & $145(7.6 \%)$ & $298(15 \cdot 1 \%)$ \\
Between 5 and 10 years & $94(6.4 \%)$ & $161(11.2 \%)$ \\
Over 10 years & $64(15.6 \%)$ & $98(21.4 \%)$ \\
\hline
\end{tabular}

Table I Difficulty in choosing diet in 28 males $(8.5 \%)$ and 99 females $(15.9 \%)$

Analysis of the data obtained in the form (Fig. 2) allowed us to define how commonly the 29 items of diet listed on the questionnaire caused upset in the function of the ileostomy.

Table II indicates the percentage of people who experienced trouble when taking the listed foods. Steak or potatoes caused trouble in less than $10 \%$ of the men and women. It was interesting to find that condiments in the form of sauces caused little upset. Items with a high content of cellulose, such as carrots, peaches and tomatoes, caused upset in only 10 to $20 \%$ of patients. We can see that alcohol was incriminated by only 20 to $30 \%$ of patients who took it. While, in general, it can be seen that males and females appeared to be affected similarly by individual foods, grilled fish was the major exception in this respect; upset was caused in only 20 to $30 \%$ of males but 40 to $50 \%$ of females complained about it. It is also clear that onion was the most troublesome item of diet listed in the enquiry while fried fish ran it a close second.

In addition to finding the number of patients who had trouble with named foods, it was also possible to relate the types of upset of ileostomy function to the ingestion of individual items of diet. Table III gives details of such relationships. Taking 'apples' as an example, it can be seen that 900 patients had taken apples since the date of operation. One hundred and twenty $(13.3 \%)$ of those had developed 'watery flow', $62(6.9 \%)$ had 'upset time of filling of bag', $58(6.4 \%)$ had had 'flatulence', $63(7.0 \%)$ had had 'pain', and nine (1\%) had had 'odour'.

'Watery flow' was caused most commonly by rhubarb (33.4\%) and alcohol (23.2\%). 'Upset time of filling of bag' was again caused most often by rhubarb $(9 \%)$ and mushrooms $(8 \%)$. 'Flatulence' occurred in $23.7 \%$ of patients who ate peas, in $22.7 \%$ after eating onions, and in $21.6 \%$ after eating beans. 'Pain' was not commonly reported, the principal foods causing pain being onion

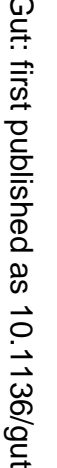




\begin{tabular}{|c|c|c|}
\hline \multirow{2}{*}{$\begin{array}{l}\text { Patients with } \\
\text { Disordered Function } \\
\text { of Ileostomy }(\%)\end{array}$} & \multicolumn{2}{|l|}{ Items Causing Upset } \\
\hline & In Men & In Women \\
\hline$<10$ & $\begin{array}{l}\text { New potatoes, potatoes, steak, } \\
\text { sauces, and cereals }\end{array}$ & Mince, potatoes, and steak \\
\hline $10-20$ & $\begin{array}{l}\text { Carrots, fried egg, mince, } \\
\text { peaches, tomatoes, pears, } \\
\text { aerated waters, and soups }\end{array}$ & $\begin{array}{l}\text { Carrots, new potatoes, cereals, } \\
\text { peaches, tomatoes, and sauces }\end{array}$ \\
\hline $20-30$ & $\begin{array}{l}\text { Apples, beetroot, boiled and } \\
\text { grilled fish, cabbage, alcohol, } \\
\text { lettuce, mushrooms, pineapple, } \\
\text { and turnips }\end{array}$ & $\begin{array}{l}\text { Apples, beetroot, fried egg, } \\
\text { peas, alcohol, aerated waters, } \\
\text { and soups }\end{array}$ \\
\hline $30-40$ & $\begin{array}{l}\text { Beans, cucumber, peas, and } \\
\text { rhubarb }\end{array}$ & $\begin{array}{l}\text { Cucumber, lettuce, mushrooms, } \\
\text { pineapple, and turnips }\end{array}$ \\
\hline $40-50$ & Fried fish & $\begin{array}{l}\text { Beans, grilled and boiled fish, } \\
\text { peas, cabbage, and rhubarb }\end{array}$ \\
\hline $\begin{array}{l}50-60 \\
60-71\end{array}$ & Onion & $\begin{array}{l}\text { Fried fish } \\
\text { Onion }\end{array}$ \\
\hline
\end{tabular}

Table III Listed items which caused upset

$(13.3 \%)$, pineapple $(11.8 \%)$, and mushroom $(9.5 \%)$. 'Odour' was the most frequently reported disorder; it was caused by onions in $38.9 \%$, while fish, whether fried, boiled, or grilled, gave rise to complaints of odour in about $30 \%$ of those who had taken fish since the date of operation.

\section{Discussion}

The 952 people who completed the questionnaire constitute a group showing, with regard to age, sex, and duration of ileostomy, a close similarity to the total membership of the Ileostomy Association of Great Britain and Ireland. It would therefore appear reasonable to assume that their experiences with the named items of diet are representative of those encountered by all patients with an ileostomy.

It is clear from this enquiry that the great majority of people with an ileostomy have no difficulty in choosing a diet. The details of the analysis have already been described, but some general conclusions may also be drawn. The fact that the vast majority $(97.5 \%)$ can maintain or increase their weight is ample evidence of the nutritious value of their diets. It is not possible to state whether the loss in weight recorded by the few $(2.5 \%)$ was causally related to the ileostomy or to independent factors.

The overall difficulty in choosing a diet appeared to rise 10 years or more after the creation of the ileostomy (Table I). It is only possible to speculate what may cause this. Do patients tire of dietary restrictions? Do they become more adventuresome and introduce items which they had previously avoided? Our data do not provide precise answers to these questions.

We are now able, however, with some measure of confidence, to offer advice to the person with an ileostomy who seeks guidance about food. He should take a mixed diet, its content being dictated by his personal choice. He should not accept advice regarding the unsuitability of items of diet without personally testing the effects on the function of the ileostomy. He should not omit any article from his diet unless he has found that it repeatedly causes dyspepsia.

We are most grateful to the members of the Ileostomy Association of Great Britain and Ireland for their cooperation in this study; also to Mr L. F. Kingston, general secretary of the Association, for supplying data regarding the members. We also thank Mr P. Waldie, senior medical photographer for preparation of the figures, and $\mathrm{Mr} \mathrm{A}$. Murray, group medical records officer, Glasgow Northern Hospitals, for his assistance in the analysis of the questionnaires.

\section{References}

Dunlop, D., Alstead, S., and Macgregor, A. G. (1968). Textbook of Medical Treatment, p. 256. Livingstone, Edinburgh and London.

Jones, F. A., Gummer, J. W. P., and Lennard-Jones, J. E. (1968). Clinical Gastroenterology, p. 661. Blackwell, Oxford and Edinburgh.

Kramer, P., Kearney, M. M., and Ingelfinger, F. J. (1962). The effect of specific foods and water loading on the ileal excreta of ileostomized human subjects. Gastroenterology, 42, 535-546. 